\title{
Bilayer Polymer Coating for Corrosion Protection of Iron Comprised of a Conductive Polymer Polyaniline and a Polymer with Triazine Rings
}

\author{
Jun Yano, ${ }^{\text {* }}$ Kazumasa NaKatani, ${ }^{\mathrm{b}}$ Yutaka HaRIma, $^{\mathrm{b}}$ and Akira KitAnI ${ }^{\mathrm{b}}$ \\ aDepartment of Engineering Science, Niihama National College of Technology (Yagumocho 7-1, Niihama, Ehime \\ 792-8580, Japan) \\ ${ }^{b}$ Faculty of Engineering, Hiroshima University (Kagamiyama 1-4-1, Higashihiroshima, Hiroshima 739-8521, Japan)
}

Received August 2, 2006 ; Accepted September 22, 2006

\begin{abstract}
A poly(2-N-phenylamino-4,6-dimercapto-S-triazine) (PPDT) layer was first prepared on the iron surface electrochemically. The PPDT layer strongly adsorbed on the surface because of the polar triazine rings of the PPDT molecules. The fact that no electrochemical response of the PPDT layer covered electrode to dissolved $\mathrm{Fe}(\mathrm{CN})_{6}{ }^{3-}$ exhibited that the PPDT layer is an insulator layer with less permeability to dissolved species, acting as a diffusion barrier against agents causing corrosion such as $\mathrm{H}_{2} \mathrm{O}$ and $\mathrm{O}_{2}$. A conductive polymer polyaniline (PANI) layer could be electrodeposited on the PPDT layer using the PPDT layer covered electrode. The obtained PANI/PPDT bilayer coating greatly lowered the anodic current peak ascribed to the anodic dissolution of iron and the corrosion current. The high anti-corrosion ability was due to a hybrid effect of the PANI layer as an in-situ oxidant and the PPDT layer as a diffusion barrier.
\end{abstract}

Key Words : Anti-corrosion, Iron, Polyaniline, Poly(2-N-phenylamino-4,6-dimercapto-S-triazine), Bilayer coating

\section{Introduction}

The corrosion of metals has long been an important problem. So far, to protect the corrosion, we mainly have had four methods: (1) simply coating the metal with a material, such as epoxy, enamel and alkyd resin, that physically impedes the agents causing corrosion; (2) the use of chemical conversion coatings such as chromates to alter the metal surface for protection; (3) cathodic protection, where a small negative potential continuously applied to the metal surface to make it passive; (4) anodic protection, where charge (e) is withdrawn from a metal to keep the metal in oxidized state rendering it passive to corrosion. Unfortunately, however, the coatings in the methods (1) and (2) are powerless against the formation of cracks and/or pinholes. On the other hand, the methods (3) and (4) are more cumbersome and expensive than most methods.

Conductive polymer coatings are more effective, cheaper and also more environmentally friendly than the methods described previously.1) Even though pinholes and/or cracks are formed in the coatings, the anti-corrosion ability is barely lowered because of the principles of the anti-corrosion coatings. Most studies have employed the oxidized form of $p$-type conductive polymers as the coatings. The coating is said to simply serve as an in-situ oxidant or anodic protectant. ${ }^{2,3)}$ At the same time that the coating oxidizes the metal surface where it is contact with, it is getting reduced itself. Since the reduced coating is re-oxidized by ambient air, it continues to oxidize the metal surface and the passive state is maintained.

Among conductive polymers, it is widely recognized that polyaniline (PANI) has been one of the best candidate conductive polymers for an anti-corrosion coating since the anti-corrosion ability was found., ${ }^{4,5}$ Although numerous studies about the anti-corrosion ability of PANI have been performed, ${ }^{5-28)}$ effort to enhance the ability should be necessary for practical use. Besides, the adhesion problem should be solved. The adhesion of electrodeposited PANI coating is generally quite poor against iron and steel. ${ }^{29)}$ In order to solve the adhesion problem as well as to enhance the anti-corrosion ability, our strategy is to employ a bilayer coating comprised of PANI and poly(2- $N$-phenylamino-4,6-dimercapto-S-triazine) (PPDT) (Fig. 1).

The key material is PPDT whose molecular structure has the triazine ring with the aniline ring. Mori and his co-workers have found that a disulfide polymer coating derived from 2-(dioctylamino)-1,3,5-triazine-4,6-dithiol (Fig. 2) shows good adhesive and anti-corrosion ability. ${ }^{30,31)}$ The polymer is an insulator and acts as a diffusion barrier. If the polymer had the aniline rings in the molecular structure, the chemical bond between PANI and the polymer could be formed. The bilayer coating would show the (a)

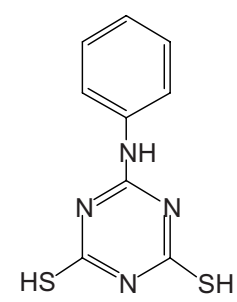

(b)<smiles>CSc1nc(Nc2ccccc2)nc(SC)n1</smiles>

Fig. 1 Molecular structure of the monomer, 2- $\mathrm{N}$ phenylamino-4, 6-dimercapto-S-triazine (a) and a probable molecular backbone of the polymer, poly(2- $N$-phenylamino4,6-dimercapto-S-triazine) (PPDT) (b). 
(a)

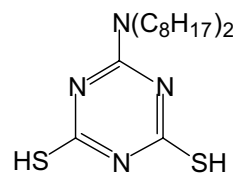

(b)

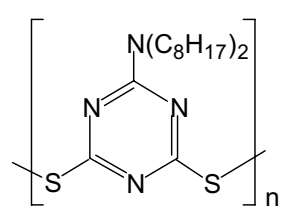

Fig. 2 Molecular structure of the monomer, 2(dioctylamino)-1, 3, 5-triazine-4, 6-dithiol (a) and a probable molecular backbone of the polymer, poly(2-(dioctylamino)-1, 3, 5-triazine-4, 6-dithiol) (b).

hybrid anti-corrosion ability of PANI and the polymer. In this paper, we electro-oxidize $2-N$-phenylamino-4,6-dimercapto-S-triazine to obtain the PPDT layer onto the iron surface. The layer is strongly adhesive to the surface because of the polar triazine rings. Furthermore, it is successful to prepare PANI on the PPDT layer, PANI/PPDT bilayer coating, by the electropolymerization of aniline using the PPDT pre-covered iron electrode. The coating shows better anti-corrosion ability than the original PANI and PPDT coatings because it behaves not only as the diffusion barrier, but also as the in-situ oxidant.

\section{Experimental}

\section{1 Materials}

One of the monomers, aniline (Wako Pure Chemicals Co.), was distilled under reduced pressure prior to use. The other monomer, 2- $N$-phenylamino-4,6-dimercapto-Striazine (Sankyo Kasei Co.), was of reagent grade and were used without further purification. Other chemicals employed in this study were of reagent grade and were used without further purification. Aqueous solutions were prepared using distilled deionized water.

The iron electrode used as the working electrode was an iron disk electrode. An iron rod cut from a commercial iron nail (\#2-080-00125) was embedded in a Tefron rod. The area of the disk electrode was $0.16 \mathrm{~cm}^{2}$. In addition, a Hokuto Denko HR-D2 Pt disk electrode was used for the electrochemical response of PPDT, PANI and PANI/PPDT bilayer covered electrodes.

\section{2 Electrochemical measurements}

An electropolymerization and three kinds of electrochemical measurements, cyclic voltammogram, linear sweep voltammogram and steady-state polarization curve, were carried out with a Hokuto Denko HZ-3000 electrochemical measurements system, using a standard three-electrode cell. A Hokuto Denko HX-C7 Pt plate electrode and a Hokuto Denko HX-R3 Ag/AgCl electrode were used as the counter and reference electrodes, respectively. All the electrochemical measurements were performed at room temperature.

\section{3 Electrodeposition of PANI and PPDT}

The electrodeposition of PANI and PPDT was made by electro-oxidizing the corresponding monomer: $0.1 \mathrm{M}$ $\left(1 \mathrm{M}=1 \mathrm{~mol} \mathrm{dm}^{-3}\right)$ aniline in an Aldrich phosphate buffer aqueous solution ( $\mathrm{pH}$ 6.86) and $5 \mathrm{mM} 2-\mathrm{N}$-phenylamino4,6-dimercapto-S-triazine in $0.1 \mathrm{M} \mathrm{Na}_{2} \mathrm{CO}_{3}$ aqueous solu-

tion. Either potential sweep $\left(-0.3 \sim+1.0 \mathrm{~V}\right.$ at $\left.50 \mathrm{mV} \mathrm{s} \mathrm{s}^{-1}\right)$ or $1.0 \mathrm{~V}$ constant-potential electrolytic mode was employed to electro-oxidize the monomer, and PANI and PPDT could be electrodeposited with any mode.

\section{1 Electrodeposition of PPDT}

\section{Results and Discussion}

To confirm whether the PPDT coating was electrodeposited, using the Pt electrode, 2- $N$-phenylamino-4,6dimercapto-S-triazine was electro-oxidized with the potential sweep method. The cyclic voltammograms (CVs) are shown in Fig. 3. The irreversible anodic current is evident at the first positive sweep, exhibiting the oxidation of the monomer. The cathodic current below 0 $\mathrm{V}$ is ascribable not to the reduction of the deposited polymer, but to the reduction of the monomer cation radicals. It is interesting to find that the anodic current increases with the potential sweep cycle number although the cathodic current decreases. This behavior suggests the electrodeposition of the polymer, PPDT.

Fig. 4 indicates the electrochemical responses of the PPDT covered Pt electrode to dissolved $\mathrm{Fe}(\mathrm{CN})_{6}{ }^{3}$. The fact that no reversible redox current peak is observed for the electrode exhibits that the electrodeposited PPDT layer is an insulator. In addition, the same electrochemical response to dissolved $\mathrm{Fe}(\mathrm{CN})_{6}{ }^{3-}$ was seen for

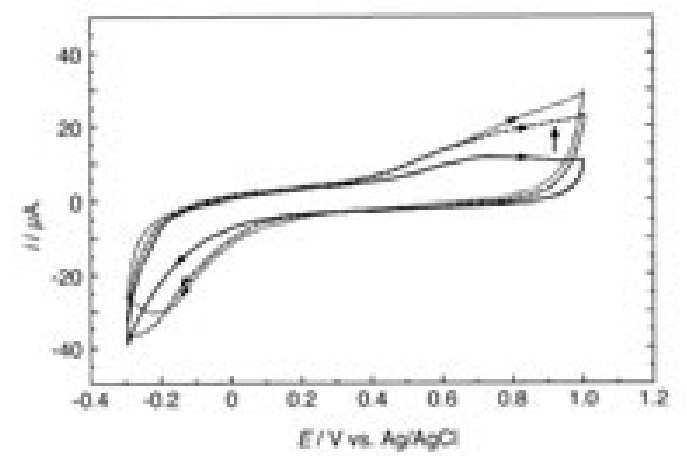

Fig. 3 Cyclic voltammograms (CVs) during the electropolymerization of the monomer, $2-\mathrm{N}$-phenylamino-4, 6dimercapto-S-triazine, in $0.1 \mathrm{M} \mathrm{Na}_{2} \mathrm{CO}_{3}$ aqueous solution at $50 \mathrm{mV} \mathrm{s}^{-1}$ measured with a Pt electrode: the first (-), the tenth (-----) and the twentieth (......) repetition cycle.

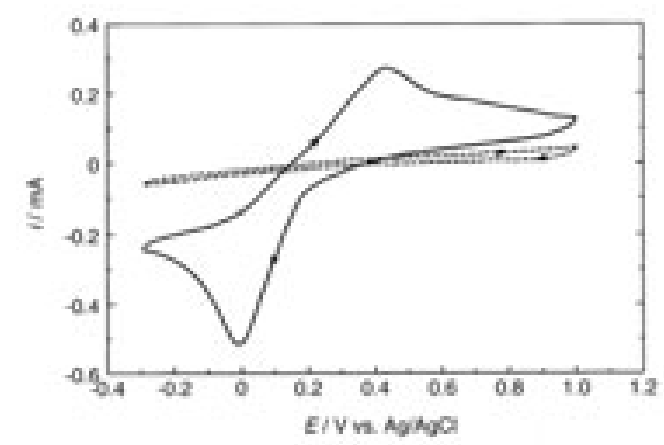

Fig. 4 Electrochemical response of the $\mathrm{Pt}(\longrightarrow)$ and the PPDT covered Pt electrode (-----) to $10 \mathrm{mM} \mathrm{K}_{3}\left[\mathrm{Fe}(\mathrm{CN})_{6}\right]$ in neutral aqueous buffer solution $(\mathrm{pH} 6.86)$ at $50 \mathrm{mV} \mathrm{s}^{-1}$. 
the PPDT covered Pt electrode prepared by the constant-potential electro-oxidation of the monomer at $1.0 \mathrm{~V}$.

To prepare the PANI/PPDT bilayer coating, aniline was electro-oxidized at $1.0 \mathrm{~V}$ using the PPDT pre-covered Pt electrode. The CV behavior of the obtained electrode is shown in Fig. 5. The redox peak current at around $0.5 \mathrm{~V}$ is due to the redox reaction of the PANI, exhibiting that PANI was electrodeposited on the PPDT electrode. Although PPDT itself is an insulator, the electron transfer through the PPDT layer takes place with electron hopping through the triazine rings. The electronic holes are generated on the triazine rings whose electron density is localized, ${ }^{30,31)}$ and the holes enable the electron hopping. In addition, the PANI layer comprised about 150 PANI molecular layers determined by the redox charge of PANI. ${ }^{32}$

\section{2 Voltammetric behavior of the bilayer covered iron}

The PPDT and PANI/PPDT bilayer coatings could also be prepared on the iron electrode in the same manner as described previously. Fig. 6 illustrates the electrochemical response of the PPDT covered iron electrode to dissolved $\mathrm{Fe}(\mathrm{CN})_{6}{ }^{3}$. No reversible redox current peak due to the $\mathrm{Fe}(\mathrm{CN})_{6}{ }^{3-} / \mathrm{Fe}(\mathrm{CN})_{6}{ }^{4-}$ redox couple is evident and the background current of iron is suppressed because the PPDT coating is an insulator and less permeable to dissolved species.

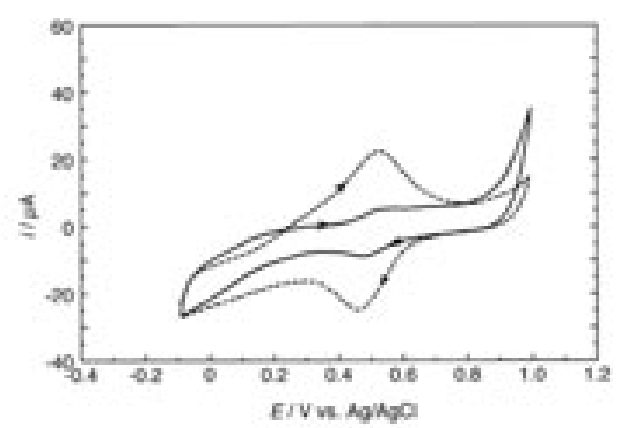

Fig. 5 CVs showing the redox activities of the PPDT layer (-) and the PANI/PPDT bilayer (-----) covered Pt electrodes. Solution: $0.1 \mathrm{M} \mathrm{H}_{2} \mathrm{SO}_{4}$ aqueous solution. Sweep rate: $50 \mathrm{mV} \mathrm{s}^{-1}$.

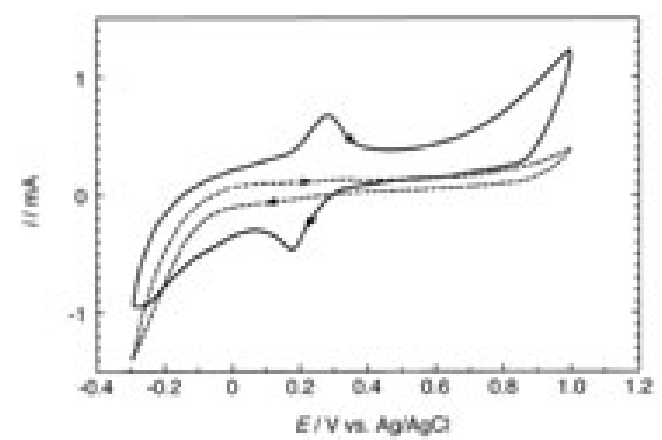

Fig. 6 Electrochemical response of the bare iron (-) and the PPDT layer-covered iron electrode (----) to $10 \mathrm{mM}$ $\mathrm{K}_{3}\left[\mathrm{Fe}(\mathrm{CN})_{6}\right]$ in neutral aqueous buffer solution $(\mathrm{pH} 6.86)$ at 50 $\mathrm{mVs}^{-1}$.
To examine how the PPDT and PANI/PPDT bilayer coatings suppress the corrosion, linear sweep voltammograms were measured with the PPDT and PANI/PPDT bilayer covered electrode in air-saturated neutral aqueous buffer solution ( $\mathrm{pH}$ 6.86). Both the PPDT and PANI/PPDT bilayer coatings were prepared by the constant-potential electro-oxidation of the corresponding monomers at $1.0 \mathrm{~V}$, where is within the potential range of the passive state of iron. The electro-oxidation was carried out until the passed charge was $1 \mathrm{mC}$. In order to avoid polarizing iron at the potential range where the oxygen evolution takes place or iron is kept in the active state, no potential sweep method was employed for the preparation of the PPDT and PANI/PPDT bilayer coatings. The linear sweep voltammograms are shown in Fig. 7. The anodic current peak at around $-0.45 \mathrm{~V}$ is ascribed to the anodic dissolution of iron. As expected, the PANI/PPDT bilayer coating suppresses the current peak most frequently.

3. 3 Effect of the PPDT thickness on the anticorrosion ability

It is important to know how thick the PPDT layer shows the best anti-corrosion ability. The thickness varied with the charge passed during the electrodeposition $\left(Q_{\mathrm{p}}\right)$. The PPDT and PANI/PPDT bilayer coatings with different $Q_{\mathrm{p}}$ were prepared on the iron electrode and the linear sweep voltammograms were measured in air-saturated neutral aqueous buffer solution $(\mathrm{pH}$ 6.86). The relationship between $Q_{\mathrm{p}}$ and the anodic peak current $\left(i_{\mathrm{pa}}\right)$ is shown in Fig. 8. The $i_{\text {pa }}$ value is roughly constant regardless of $Q_{\mathrm{p}}$ although it slightly fluctuates. This suggests that thin PPDT layer is adequate to acquire the anti-corrosion ability. In addition, the thickness of the PANI layer corresponding to $Q_{\mathrm{p}}$ of $0.2 \mathrm{mC}$ was adequate to show the same anti-corrosion.

In order to determine the kinetic parameters, the corrosion current $\left(i_{\text {corr }}\right)$ and potential $\left(E_{\text {corr }}\right)$, the steady-state polarization curves were measured for the PPDT and PANI/PPDT bilayer coatings in acidic and neutral aqueous solutions. The typical Tafel plots obtained from the polarization curves are shown in Fig. 9. The oxidation and reduction branches of the curves are well defined. The extrapolation of the Tafel regions of the cathodic

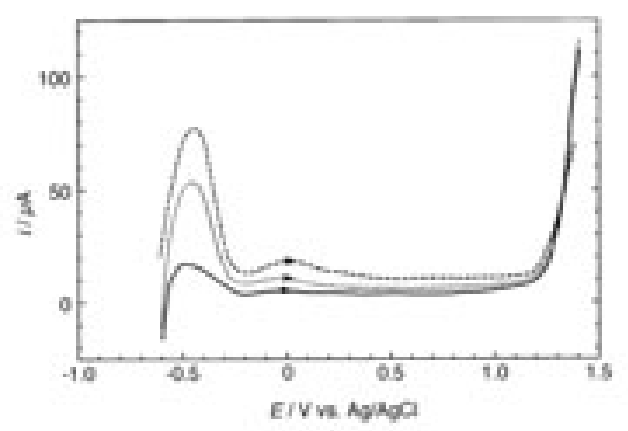

Fig. 7 Linear sweep voltammograms at $5 \mathrm{mV} \mathrm{s}^{-1}$ measured with the bare iron (----), PPDT layer (......) and PANI/PPDT bilayer $(-)$ covered electrodes in neutral aqueous buffer solution (pH 6.86). 
and anodic polarization curves is used to obtain $i_{\text {corr }}$ and $E_{\text {corr. }}$. It yields a smaller $i_{\text {corr }}$, reflecting the anti-corrosion ability (Table 1).

The Tafel plots for air-saturated acidic $\left(0.5 \mathrm{M} \mathrm{H}_{2} \mathrm{SO}_{4}\right)$ and neutral aqueous solution $\mathrm{pH} 6.86$ phosphate buffer

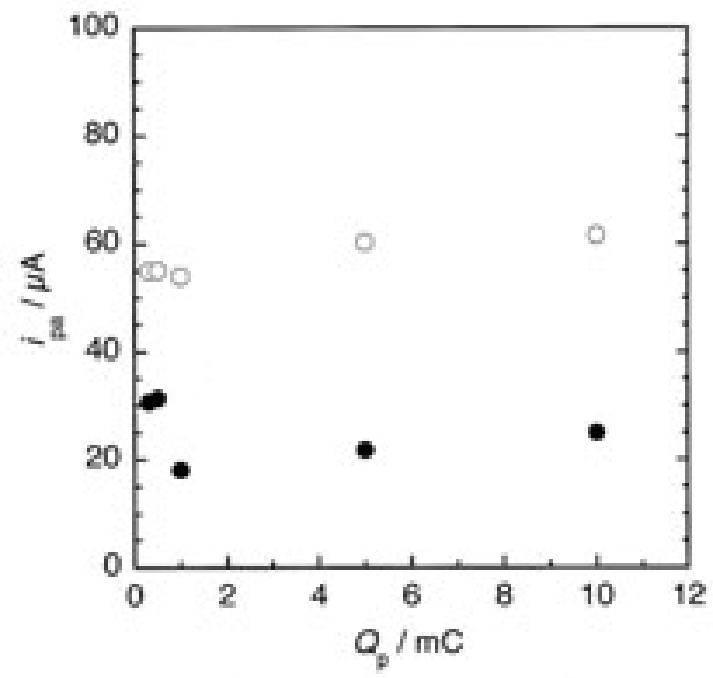

Fig. 8 Relationship between the charge passed during the electrodeposition of PPDT layer $\left(Q_{\mathrm{p}}\right)$ and the anodic peak current ascribed to the anodic dissolution of iron $\left(i_{\mathrm{pa}}\right)$.

(○): PPDT covered iron electrode. (O): PANI/PPDT bilayer covered electrode.

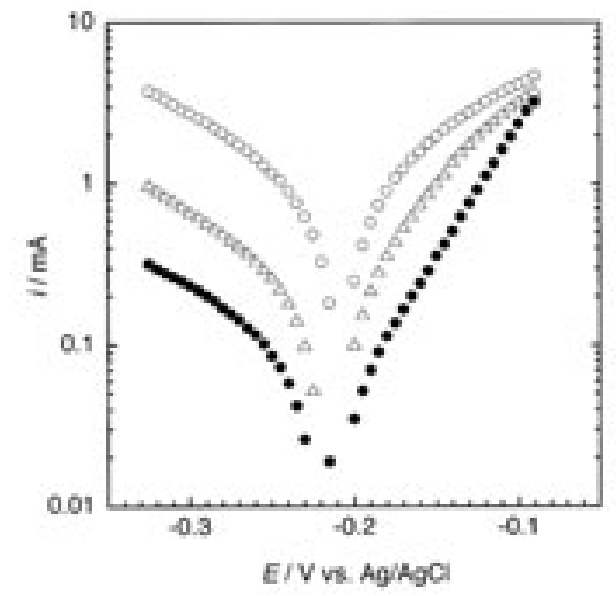

Fig. 9 Tafel plots obtained from the polarization curves measured with the bare iron $(\bigcirc), \operatorname{PPDT}(\triangle)$ and PANI/PPDT bilayer (O) covered electrodes in $0.5 \mathrm{M} \mathrm{H}_{2} \mathrm{SO}_{4}$ aqueous solution.

Table 1 Corrosion current $\left(i_{\text {corr }}\right)$ and potential $\left(E_{\text {corr }}\right)$ determined by the extrapolation of the Tafel regions of the cathodic and anodic polarization curves in Fig. 9.

\begin{tabular}{ccc}
\hline Coating & $E_{\text {corr }} / \mathrm{V}$ vs. $\mathrm{Ag} / \mathrm{AgCl}$ & $i_{\text {corr }} / \mathrm{mA}$ \\
\hline None & -0.212 & 0.75 \\
PPDT layer & -0.229 & 0.23 \\
PANI/PPDT bilayer & -0.209 & 0.06 \\
\hline
\end{tabular}

solution) were obtained for the PPDT and PANI/PPDT bilayer coatings with the different thickness of the PPDT layer estimated by $Q_{\mathrm{p}}$. The effect of the PPDT thickness (i.e. $Q_{\mathrm{p}}$ ) on $i_{\text {corr }}$ is shown in Fig. 10 for the acidic solution and Fig. 11 for the neutral solution. It is noteworthy that even the thin thickness corresponding to $0.5 \mathrm{mC}$ greatly suppresses $i_{\text {corr }}$ compared to the case without the coatings (see Table 1 ). For any media, $i_{\text {corr }}$ gradually decreases with $Q_{\mathrm{p}}$ and levels out when $Q_{\mathrm{p}}>5$ $\mathrm{mC}$.

As described previously, the PPDT and PANI/PPDT bilayer coating was found to show greater anti-corrosion

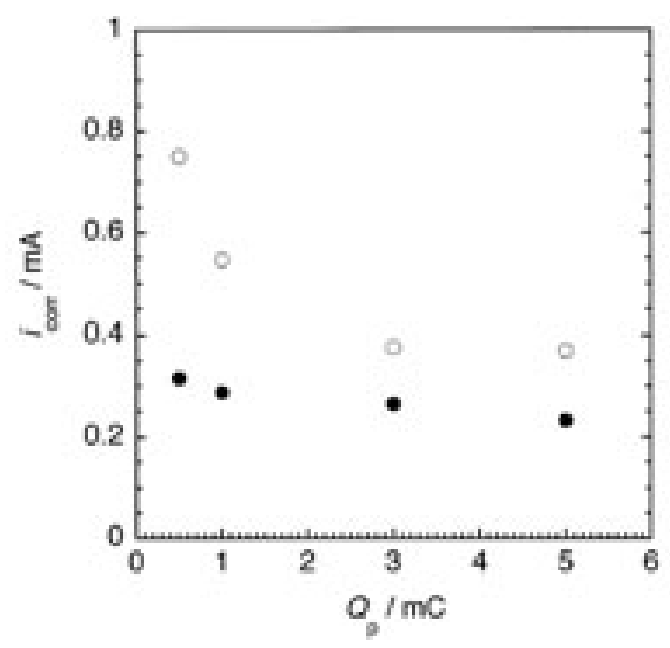

Fig. 10 Relationship between the charge passed during the electrodeposition of PPDT $\left(Q_{\mathrm{p}}\right)$ in the PANI/PPDT bilayer coating and the corrosion current $\left(i_{\text {corr }}\right)$ in acidic medium (0.5 $\mathrm{M} \mathrm{H}_{2} \mathrm{SO}_{4}$ aqueous solution).

(○): PPDT covered iron electrode. (O): PANI/PPDT bilayer covered electrode.

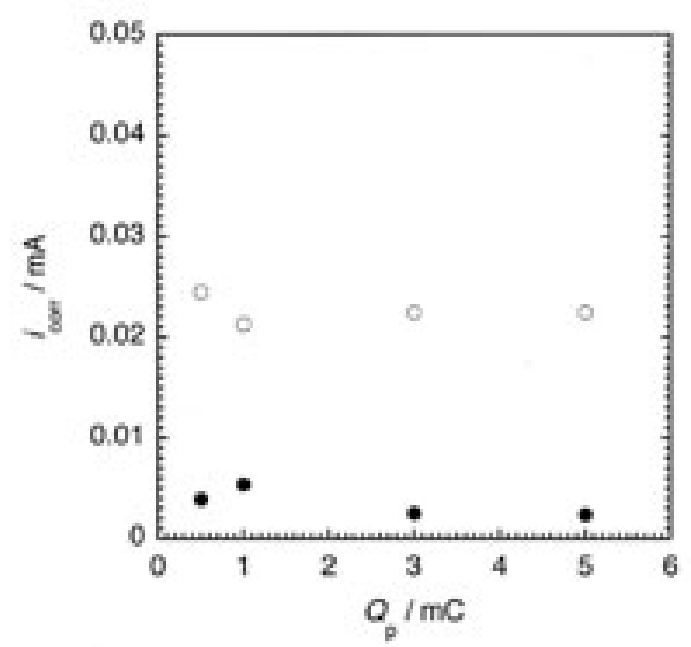

Fig. 11 Relationship between the charge passed during the electrodeposition of PPDT $\left(Q_{\mathrm{p}}\right)$ in the PANI/PPDT bilayer coating and the corrosion current $\left(i_{\text {corr }}\right)$ in neutral medium (buffer solution of $\mathrm{pH}$ 6.86). (○): PPDT covered iron electrode. (O): PANI/PPDT bilayer covered electrode. 
ability than the PPDT and PANI coatings. Besides, unlike the PANI coating, the PANI/PPDT bilayer coating did not peel off, but adhered to the iron electrode surface even after several polarization experiments such as Fig. 9. Thus the PANI/PPDT bilayer coating is an effective to solve the adhesion problem as well as to enhance the anti-corrosion ability.

\section{4 Role of the PPDT layer in the anti-corrosion} ability

Several mechanisms of the anti-corrosion of the PANI coating have been proposed. According to most mechanisms, PANI is considered to act as the in-situ oxidant. The oxidized form of PANI oxidizes the iron surface where it is contact with, it is getting reduced form itself. Since the reduced form is re-oxidized by ambient air, it continues to oxidize the iron surface and the passive state is maintained.

On the other hand, the PPDT layer plays three important roles: (1) diffusion barrier, (2) adhesive binder and (3) electron transfer medium between the iron substrate and the PANI layer. The PPDT layer is an insulator layer with less permeability to dissolved species, ${ }^{30,31)}$ acting as the diffusion barrier. The barrier physically impedes the agents causing corrosion such as $\mathrm{H}_{2} \mathrm{O}, \mathrm{O}_{2}$ and salt. The PPDT layer adsorbs on the iron substrate more strongly than PANI because of the polar triazine rings of the PPDT molecules. The electron transfer through the PPDT layer occurs by the electron hopping with the localized electron density of the triazine ring. ${ }^{30,31)}$ This proposed mechanism is schematically depicted in Fig. 12. The key material, PPDT, is expected to prepare other bilayer coatings containing different conductive polymers and to be applied to various metal corrosions because of the novel and unique properties.

\section{Conclusions}

To protect iron from corrosion, a bilayer polymer coat-

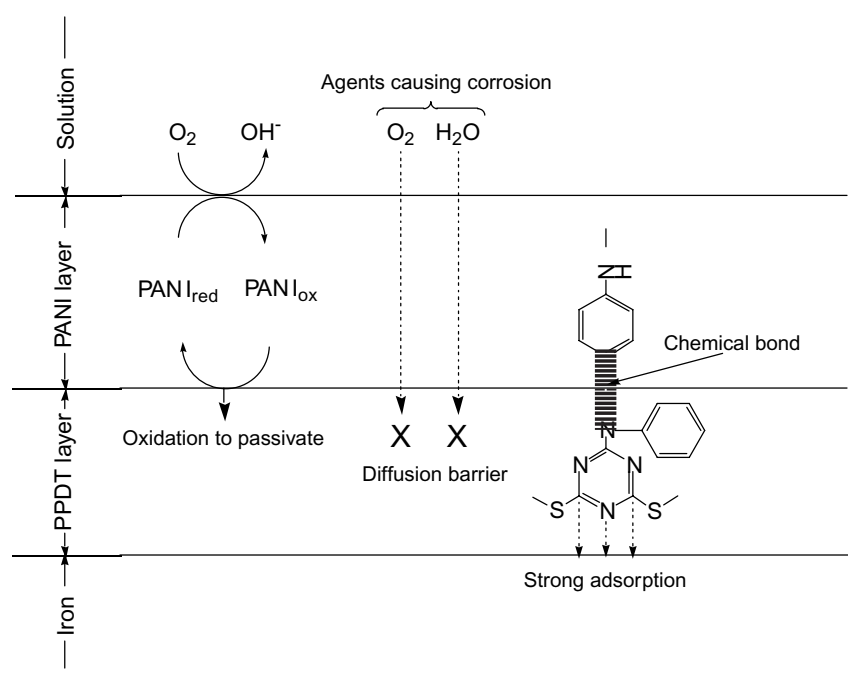

Fig. 12 Schematic depiction explaining the anti-corrosion mechanism of the PANI/PPDT bilayer coating on the iron surface. ing comprised of a conductive polymer, polyaniline (PANI), and poly(2-N-phenylamino-4,6-dimercapto-S-triazine) (PPDT) was electrochemically prepared on the iron surface. The key material, the PPDT layer, plays three important roles: (1) diffusion barrier, (2) adhesive binder and (3) electron transfer medium between the iron substrate and the PANI layer. The PPDT layer is an insulator layer with less permeability to dissolved species, acting as the diffusion barrier. The barrier physically impedes the agents causing corrosion such as $\mathrm{H}_{2} \mathrm{O}$ and $\mathrm{O}_{2}$. The PPDT layer adsorbs on the iron substrate more strongly than PANI because of the polar triazine rings of the PPDT molecules. The amino groups of the PPDT molecules enable to combine the PPDT molecules with the PANI molecules chemically. The electron transfer through the PPDT layer takes place by the electron hopping with the localized electron density of the triazine ring. As a result, the PANI/PPDT bilayer coating protects the corrosion electrochemically as well as physically. The key material, PPDT, is expected to prepare other bilayer coatings containing different conductive polymers and to be applied to various metal corrosions because of the novel and unique properties.

\section{Acknowledgements}

Helpful discussion with Professor Yoshinori Kanno of Yamanashi University is gratefully acknowledged.

\section{References}

1) P. Chandrasekhar, Conducting Polymers, Fundamentals and Applications (Kluwer Academic Publishers, London, UK) p.573 (1999).

2) N. Ahmad and A. G. MacDiarmid, Synth. Met., 78, 103 (1996).

3) N. Ahmad and A. G. MacDiarmid, U. S. Patent, 5645890 (1997).

4) G. Mengoli, M. Munari, P. Bianco, and M. Musiani, $J$. Appl. Polym. Sci., 26, 4247 (1981).

5) D. W. DeBerry, J. Electrochem. Soc., 132, 1022 (1985).

6) A. G. MacDiarmid, J. C. Chiang, A. F. Richter, N. L. D. Somasiri and A. J. Epstein, in L. Alcear ed., Conducting Polymer, D. Reidel Publishing, Dodrecht, Netherlands, p.105 (1987).

7) Z. Deng, W. H. Smyrl, and H. S. White, J. Electrochem. Soc., 136, 2152 (1989).

8) G. Troch-Nagels, R. Winand, A. Weyneersch, and L. Renard, J. Appl. Electrochem., 22, 756 (1992).

9) B. Wessling, Adv. Mater., 6, 226 (1994).

10) W. Lu, R. L. Elsenbaumer, and B. Wessling, Synth. Met., 71, 2163 (1995).

11) J. L. Camalet, J. C. Lacroix, S. Aeiyach, K. Chane-Ching, and P. C. Lacaze, J. Electroanal. Chem., 416, 179 (1996).

12) M. Fahlman, S. Jasty, and A. J. Epstein, Synth. Met., 85, 1323 (1997).

13) P. J. Kinlen, D. C. Silverman, and C. R. Jeffreys, Synth. Met., 85, 1327 (1997).

14) A. Talo, P. Passiniemi, O. Forsén and S. Yläsaari, Synth. Met., 85, 1333 (1997).

15) J. L. Camalet, J. C. Lacroix, S. Aeiyach, K. Chane-Ching, and P. C. Lacaze, Synth. Met., 93, 133 (1998).

16) J. L. Camalet, J. C. Lacroix, S. Aeiyach, K. Chane-Ching, and P. C. Lacaze, J. Electroanal. Chem., 445, 117 (1998). 
17) J. R. Santos, Jr, L. H. C. Mattoso, and A. J. Motheo, Electrochim. Acta, 43, 309 (1998).

18) B. Wessling and J. Posdorfer, Electrochim. Acta, 44, 2139 (1999).

19) P. J. Kinlen, V. Menon, and Y. Ding, J. Electrochem. Soc., 146, 3690 (1999).

20) D. E. Tallman, Y. Pae, and G. P. Bierwagen, Corrosion, 55, 779 (1999).

21) M. C. Bernard, A. H. Goff, S. Joiret, N. N. Dinh, and N. N. Toan, J. Electrochem. Soc., 146, 995 (1999).

22) M. C. Bernard, C. Deslouis, T. E. Moustafid, A. H. Goff, S. Joiret, and B. Tribollet, Synth. Met., 102, 1381 (1999).

23) M. C. Bernard, A. H. Goff, S. Joiret, N. N. Dinh, and N. N. Toan, Synth. Met., 102, 1383 (1999).

24) M. C. Bernard, S. Joiret, A. H. Goff, and P. V. Phong, J. Electrochem. Soc., 148, B299 (2001).

25) M. C. Bernard, S. Joiret, A. H. Goff, and P. V. Phong, J.
Electrochem. Soc., 148, B304 (2001).

26) W. S. Araujo, J. C. P. Margarit, M. Ferreira, O. R. Mattos, and P. L. Neto, Electrochim. Acta, 46, 1307 (2001).

27) R. Gasprac and C. R. Martin, J. Electrochem. Soc., 148, B138 (2001).

28) R. Gasprac and C. R. Martin, J. Electrochem. Soc., 149, B409 (2002).

29) A. Meneguzzi, M. C. Pham, J. Lacroix, B. Piro, A. Adenier, C. A. Ferreira, and P. Lacaze, J. Electrochem. Soc., 148, B121 (2001).

30) K. Mori, Hyomen Gijutu, 51, 276 (2000) [in Japanese].

31) K. Mori, Y. Sasaki, S. Sai, S. Kaneda, H. Hirahara, and Y. Oishi, Langmuir, 11, 1431 (1995).

32) This value was determined based on the redox charge of the PANI layer. 